\title{
Pemodelan dan Analisis Berdasarkan Studi Eksperimental Pengaruh Modifikasi Profil Gigi Terhadap Karakteristik Dinamis pada Involute Spur Gear
}

\author{
Prasetyo Putra Wibowo dan Agus Sigit Pramono \\ Departemen Teknik Mesin, Fakultas Teknologi Industri, Institut Teknologi Sepuluh Nopember (ITS) \\ e-mail: pramono@me.its.ac.id
}

\begin{abstract}
Abstrak-Roda gigi atau gear merupakan salah satu elemen mesin yang berfungsi untuk mentransmisikan daya. Sumber transimisi sebuah gear berasal dari kontak dan gesekan yang terjadi pada pasangan gear yang diteruskan oleh porosnya. Kontak dan gesekan yang terjadi merupakan sumber utama kegagalan pada roda gigi apabila dipadukan dengan kesalahan-kesalahan (error) dalam perancangan, assembly, dan machining roda gigi. Usaha yang dapat dilakukan untuk mengurangi masalah tersebut adalah dengan memodifikasi profil gigi dengan bentuk tip relief pada involute spur gear. Tip relief adalah pemotongan bagian flank pada roda gigi dengan bentuk parabolik dan linier. Material yang digunakan untuk penelitian ini adalah $\mathrm{S45C}$. Simulasi regangan dinamis dilakukan dengan analisa Transient Structure, sedangkan analisa getaran dilakukan dengan analisa Harmonic Response pada software FEA. Hasil yang didapatkan dari penelitian ini adalah terjadi reduksi nilai regangan dan getaran pada profil modifikasi parabolik dan linier. Nilai reduksi yang terjadinya selanjutnya dibandingkan dengan hasil eksperimen dan didapatkan error dari simulasi yang dilakukan. Hasil dari penelitian ini diharapkan dapat menjadi solusi pada perindustrian terhadap kesalahan proses assembly dan machining yang terjadi pada pasangan roda gigi.
\end{abstract}

Kata Kunci-Involute spur gear, tip relief, regangan dinamis, getaran, finite element method.

\section{PENDAHULUAN}

A KTIVIS perindustrian umumnya menggunakan mesinmesin berkapasitas besar dan memiliki umur yang panjang. Kinerja mesin tersebut sangat dipengaruhi dari kondisi komponennya, khususnya pada gearbox-nya. Gearbox sendiri terdiri dari susunan roda gigi yang disusun sedemikian rupa agar dapat mentransmisikan daya secara optimum Roda gigi atau gear adalah elemen mesin yang berfungsi untuk mentransmisikan daya. Daya yang ditransmisikan berasal dari kontak dan gesekan yang terjadi antar gear, kemudian diteruskan oleh porosnya. Selain roda gigi, terdapat pula rantai dan belt yang memiliki fungsi mentransmisikan daya. Namun, dibandingkan dua pilihan tersebut, roda gigi memiliki keuntungan [1], yaitu :

a) Reliability yang lebih tinggi

b) Kemampuan menerima beban yang lebih tinggi

c) Efisiensi lebih baik, karena kemungkinan slip kecil

d) Sistem transmisi ringkas dengan putaran dan daya lebih besar
Secara umum kegagalan yang terjadi pada roda gigi adalah wear, surface fatigue, dan plastic wear, yang disebabkan tegangan kontak dan beakage yang dihasilkan tegangan bending, apalagi jika dipadukan dengan kesalahan-kesalahan (error) dalam perancangan, pemasangan, dan manufaktur roda gigi Jika roda gigi pada ini mengalami kerusakan, maka akan terjadi kerusakan yang lebih buruk pada komponen lain dari mesin tersebut. Kondisi ini dapat menyebabkan proses produksi terhenti dan menyebabkan kerugian biaya yang sangat besar. Upaya yang dapat dilakukan untuk mengurangi masalahmasalah tersebut adalah dengan memodifikasi profil gigi pada gear.

Penelitian ini menggunakan bentuk modifikasi tip relief dengan bentuk profil parabolik dan linier. Material yang digunakan untuk penelitian ini adalah S45C. Pasangan gear ini selanjutnya dimodelkan secara 3D dengan software Computer Aided Design (CAD), lalu dianalisa dengan software Finite Element Analysis (FEA). Analisa regangan dinamis dilakukan dengan menggunakan analisa Transient Structure, sedangkan analisa getaran dilakukan dengan menggunakan analisa Harmonic Response. Analisa regangan dinamis dilakukan dengan variasi 100, 200, dan $300 \mathrm{rpm}$, sedangkan analisa getaran dilakukan dengan variasi 200, 300, 400, 500, dan 600 rpm.

Penelitian terdahulu yang dilakukan oleh Aditya, Novreza [2] memodelkan serta menganalisis perubahan distribusi tegangan pada spur gear dengan bentuk profil involute dan cycloid, hasilnya didapatkan bahwa tegangan pada profil gigi involute 1,23 kali lebih besar dari cycloid. Sementara itu, penelitian yang dilakukan oleh Pramono, Agus Sigit [3] melakukan pembuatan, modifikasi, serta pengujian pada involute spur gear dengan jenis profil seperti profil standard, modifikasi parabolik sedang, modifikasi parabolik panjang, dan modifikasi linier. Bentuk modifikasi yang dilakukan menghasilkan regangan dinamis serta getaran yang lebih rendah bila dibandingkan dengan profil standard dari involute spur gear. Sementara itu, penelitian yang dilakukan oleh Temis, Y., Kozharinov E., dan Kalinin D [4] melakukan analisa tegangan dan getaran dengan bantuan software FEA, hasil yang didapatkan pada penelitian ini menunjukkan terjadinya diskontinuitas getaran akibat hilangnya kontak pada gigi pada critical range melalui frequency response, sedangkan pada metode finite element didapatkan distribusi beban pada fase teeth meshing (kondisi pada saat roda gigi saling bertautan). 


\section{URAIAN PENELITIAN}

A. Pemodelan

Tabel 1.

Data Geometri Involute Spur Gear

\begin{tabular}{ccc}
\hline \hline PARAMETER & SIMBOL & NILAI \\
\hline Pitch Circle Diameter & $\mathrm{dp}$ & $72 \mathrm{~mm}$ \\
Number of Teeth & $\mathrm{Nt}$ & 18 \\
Pressure Angle & $\theta$ & $20^{\circ}$ \\
Module & $\mathrm{m}$ & $4 \mathrm{~mm}$ \\
Addendum & $\mathrm{a}$ & $4 \mathrm{~mm}$ \\
Dedendum & $\mathrm{b}$ & $5 \mathrm{~mm}$ \\
Clearance & $\mathrm{c}$ & $1 \mathrm{~mm}$ \\
Lebar Gigi & $\mathrm{w}$ & $6 \mathrm{~mm}$ \\
Material & - & S45C \\
Rasio Reduksi Putaran & - & 2 \\
\hline \hline
\end{tabular}

Tabel 2.

Data Material S45C

\begin{tabular}{ccc}
\hline \hline ISTILAH & SATUAN & NILAI \\
\hline Massa Jenis & $\mathrm{kg} / \mathrm{m}^{3}$ & $7700-8030$ \\
Young Modulus & $\mathrm{GPa}$ & $190-210$ \\
Tensile Strength & $\mathrm{MPa}$ & 569 \\
Yield Strength & $\mathrm{MPa}$ & 343 \\
Poisson Ratio & - & $0.27-0.30$ \\
Elongation & - & $>20 \%$ \\
Hardness & $\mathrm{HB}$ & $167-229$ \\
Strength Exponent & - & -0.106 \\
Ductilility Coefficient & - & -0.47 \\
Thermal Conductivity & $\mathrm{W} / \mathrm{mK}$ & 49.8 \\
Specific Heat & $\mathrm{J} / \mathrm{kgK}$ & 486 \\
\hline \hline
\end{tabular}

Pemodelan dilakukan dengan menggunakan data geometri dan material yang tertera pada referensi [3]. Data geometri ditunjukkan oleh tabel 1, sementara data material ditunjukkan dengan tabel 2.

Bentuk Modifikasi Parabolik memiliki persamaan sebagai berikut :

$$
\begin{array}{ll}
\mathrm{L}=-0,0005 \mathrm{x}^{\wedge} 2+0,6173 \mathrm{x}-0,3382 & \text { untuk pinion, } \\
\mathrm{L}=-0,0013 \mathrm{x}^{\wedge} 2+1,2369 \mathrm{x}-0,5667 & \text { untuk gear }
\end{array}
$$

Bentuk Modifikasi Linier memiliki persamaan sebagai berikut :

$$
\begin{array}{ll}
L=0,5747 x+0,4697 & \text { untuk pinion } \\
L=1,1603 x+0,5382 & \text { untuk gear }
\end{array}
$$

Proses design sendiri diawali dengan membuat sketch lingkaran terluar dari gear, kemudian menggunakan fitur extrude, lalu membuat sketch kurva involute, kemudian melakukan trimming dan mirroring profil kurva, selanjutnya menggunakan fitur circular pattern, dan terkahir membuat lubang untuk poros pada kedua gear.

Proses aseembly sendiri terdiri dari pembuatan sketch base sebagai peletakan pasangan gear, insert komponen, float pada salah satu komponen gear, front plane pada gear dengan front plane pada sketch base dengan fitur concident mate, dan terakhir menggunakan gear mate sebagai penghubung mekanisme.

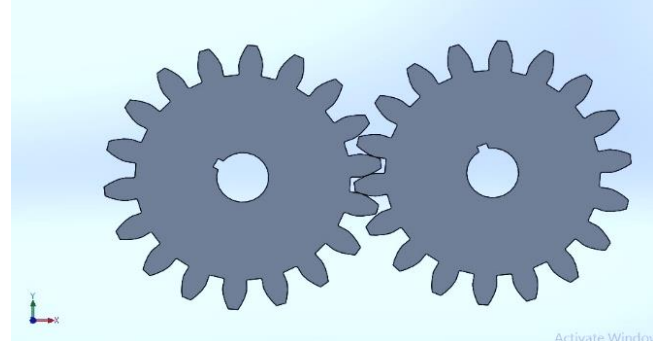

Gambar 1. Hasil Proses Design dan Assembly pada software CAD

\section{B. Simulasi}

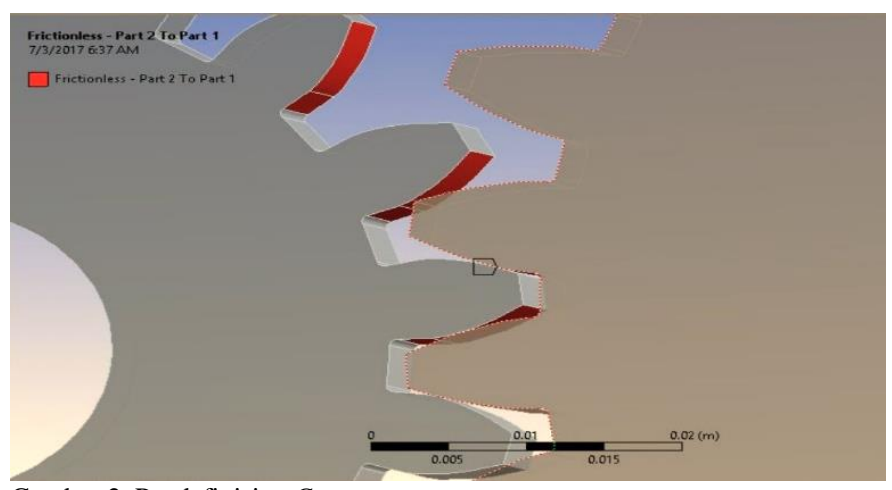

Gambar 2. Pendefinisian Contact

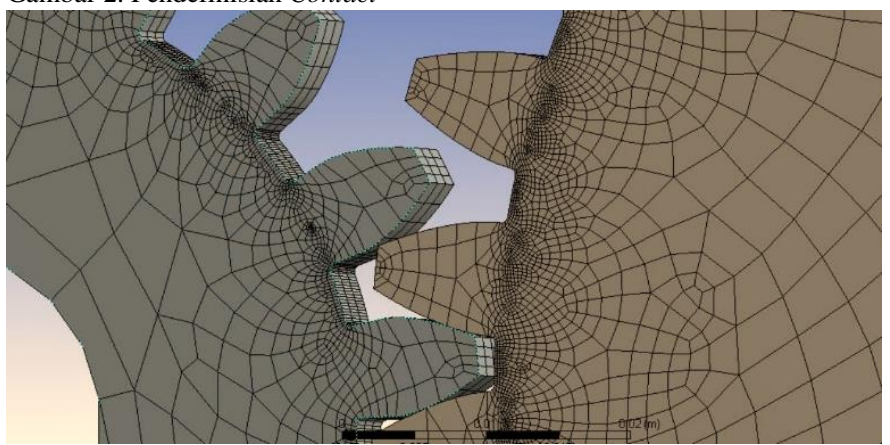

Gambar 3. Hasil Meshing Involute Spur Gear

Pendefinisian kondisi batas pada simulasi regangan dinamis terdiri dari penentuan contact, joint, meshing dan time setting. Tipe contact yang ditunjukkan pada gambar 6 adalah tipe frictionless dengan peletakan pada bagian pertautan kontak antar gigi, lalu tipe joint yang digunakan adalah tipe joint revolute body to ground dengan pusat joint diletakkan pada lubang poros pasangan gear. Pengaturan meshing seperti pada gambar 7 terdiri dari edge sizing pada kurva dan tebal gear, lalu face sizing pada bagian clearance dari kaki gigi.

Pengaturan time setting seperti pada tabel 3 dilakukan pada simulasi Trasient Structure untuk mengetahui perubahan regangan yang terjadi tiap waktunya. Initial Time Step ditentukan berdasarkan frekuensi natural dari pasangan gear dengan menggunakan persamaan 1/(20.f), penentuan Minimum Time Step dilakukan berdasarkan ketelitian yang diinginkan dari perubahan regangan tiap waktunya, dan Step End Time ditentukan untuk menentukan jumlah step yang diinginkan pada simulasi.

Pada simulasi Harmonic Response pengaturan dilakukan pada Analysis Setting untuk mendapatkan spektrum getaran terhadap perubahan frekuensi, seperti yang terlihat pada tabel 4. Data spektrum yang diambil dilakukan pada range $0-300 \mathrm{~Hz}$, seperti pada referensi [3] dengan interval 60 titik pengambilan data.

Tabel 3.

Time Setting pada Transient Structure

\begin{tabular}{cc}
\hline \hline STEP CONTROLS & ANALYSIS SETTINGS \\
\hline Number of Steps & 1 \\
Current Step Number & 1 \\
Step End Time & $9.13 \mathrm{e}-003 \mathrm{~s}$ \\
Auto Time Setting & On \\
Define By & Time \\
Initial Time Step & $8.3 \mathrm{e}-004 \mathrm{~s}$ \\
Minimum Time Step & $8.3 \mathrm{e}-006 \mathrm{~s}$ \\
\hline \hline
\end{tabular}




\begin{tabular}{cc}
\hline \hline $\begin{array}{c}\text { Maximum Time Step } \\
\text { Time Integration }\end{array}$ & $\begin{array}{c}8.3 \mathrm{e}-004 \mathrm{~s} \\
\text { On }\end{array}$ \\
\hline \multicolumn{2}{c}{ Tabel 4. } \\
\multicolumn{2}{c}{ Analysis Setting pada Harmonic Response } \\
\hline \hline ANALYSIS SETTING & VALUE \\
\hline Frequency Spacing & Linier \\
Range Minimum & $0 \mathrm{~Hz}$ \\
Range Maximum & $300 \mathrm{~Hz}$ \\
Solution Interval & 60 \\
Solution Method & Mode Superposition \\
\hline \hline
\end{tabular}

\section{HASIL DAN PEMBAHASAN}

\section{A. Analisis Regangan Dinamis}

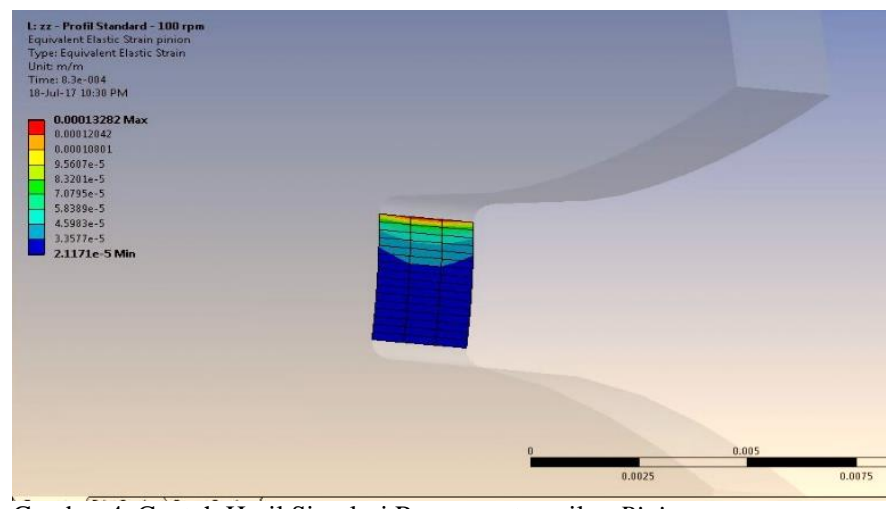

Gambar 4. Contoh Hasil Simulasi Regangan tampilan Pinion

Nilai yang diperoleh melelui hasil simulasi ditunjukkan dengan warna-warna tertentu seperti pada gambar 5 yang menunjukkan rentang nilai minimum sampai dengan nilai maksimum yang terjadi pada model 3D roda gigi

Pengambilan data simulasi diletakkan pada bagian kaki gigi, menyesuaikan dengan letak pengambilan data yang dilakukan pada referensi [3]. Gambar 11 merupakan salah salu olahan data hasil simulasi untuk melihat trendline yang terjadi pada hasil simulasi. Pengolahan data ini dilakukan pada kedua pasangan gigi dengan variasi 100, 200, dan $300 \mathrm{rpm}$. Trendline yang terjadi pada hasil simulasi memiliki kesamaan bentuk dan profil bila dibandingkan dengan hasil eksperimen. Setelah melihat bentuk trendline pada hasil simulasi, nilai regangan dinamis maksimal pada tiap roda gigi dan variasi diolah kembali untuk mengetahui pengaruh dari modifikasi profil gigi yang telah dilakukan. Hasil olahan data tersebut ditunjukkan pada gambar 12.

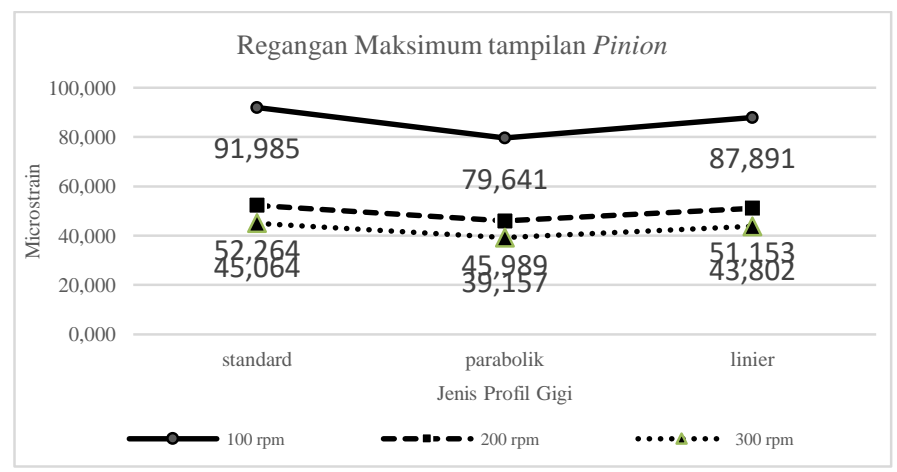

Gambar 11. Contoh Grafik Hasil Olahan Data Simulasi

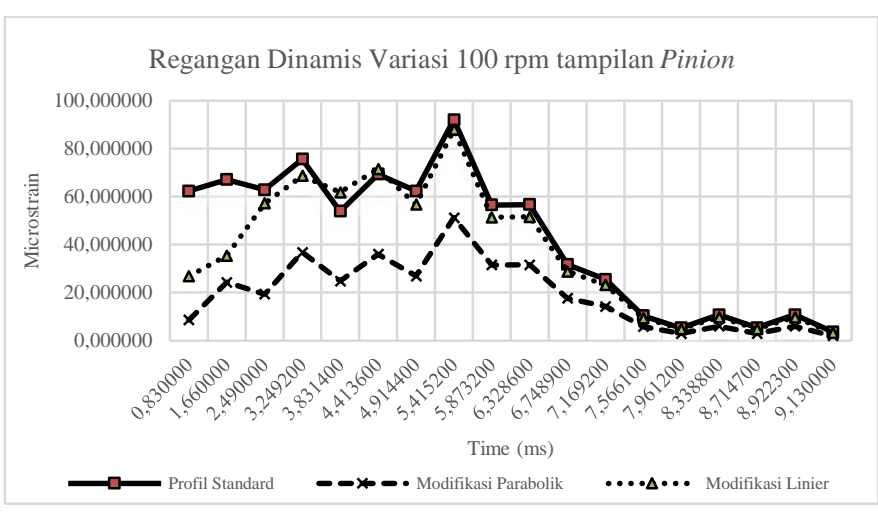

Gambar 12. Contoh Nilai Regangan Maksimum tampilan Pinion

Data regangan dinamis maksimal selanjutnya diolah dan dibandingkan dengan hasil eksperimen untuk mengetahui besar error yang terjadi pada penelitian ini. Perbandingan dan error hasil simulasi dan eksperimen ditunjukkan pada tabel 5.

Tabel 5.

Perbandingan Regangan Maksimum dan error

\begin{tabular}{|c|c|c|c|c|c|c|c|}
\hline \multirow{5}{*}{$\begin{array}{l}\text { : } \\
\text { : } \\
\stackrel{8}{0}\end{array}$} & \multicolumn{3}{|c|}{ simulasi (microstrain) } & \multicolumn{2}{|c|}{ eksperimen } & \multicolumn{2}{|c|}{ error $(\%)$} \\
\hline & & pinion & gear & pinion & gear & pinion & gear \\
\hline & standard & 91.99 & 59.88 & 69.57 & 38.33 & 9.75 & 14.39 \\
\hline & parabolik & 79.64 & 36.69 & 44.51 & 21.76 & 17.64 & 16.28 \\
\hline & linier & 87.89 & 28.85 & 54.24 & 17.31 & 15.31 & 16.00 \\
\hline$\Xi$ & standard & 52.26 & 27.38 & 39.40 & 14.48 & 9.85 & 18.84 \\
\hline$\frac{5}{8}$ & parabolik & 45.99 & 25.27 & 21.93 & 11.70 & 20.93 & 21.48 \\
\hline ते & linier & 51.15 & 23.03 & 31.32 & 9.89 & 15.51 & 22.82 \\
\hline$\Xi$ & standard & 45.06 & 14.69 & 24.73 & 9.89 & 18.05 & 13.06 \\
\hline 2 & parabolik & 39.16 & 30.64 & 24.73 & 13.68 & 14.74 & 22.14 \\
\hline & linier & 43.80 & 12.91 & 20.61 & 8.24 & 21.18 & 14.48 \\
\hline & \multicolumn{5}{|c|}{ rata-rata error } & 15.88 & 17.72 \\
\hline
\end{tabular}

\section{A. Analisis Getaran}

Nilai yang diperoleh melelui hasil simulasi ditunjukkan dengan grafik amplitudo-frekuensi yang menunjukkan rentang nilai minimum sampai dengan nilai maksimum yang terjadi pada model 3D roda gigi, seperto yang ditunjukkan pada gambar 13 .

$$
\text { Graph }
$$

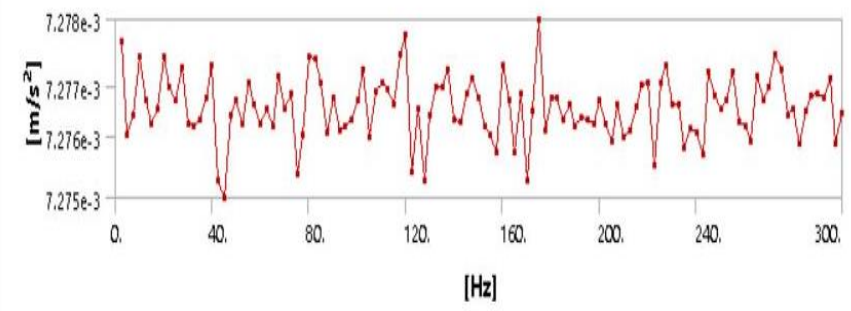

Gambar 13. Contoh Nilai Getaran Hasil Simulasi tampilan Pinion

Pengambilan nilai simulasi dilakukan pada bagian terluar lubang poros, untuk mendapatkan hasil yang cukup sesuai dengan yang dilakukan pada penelitian [3]. Nilai getaran yang didapatkan pada hasil simulasi kemudian diolah dalam bentuk 
grafik untuk mengetahui perubahan getaran yang terjadi pada tiap variasi, ditunjukkan pada gambar 14 .

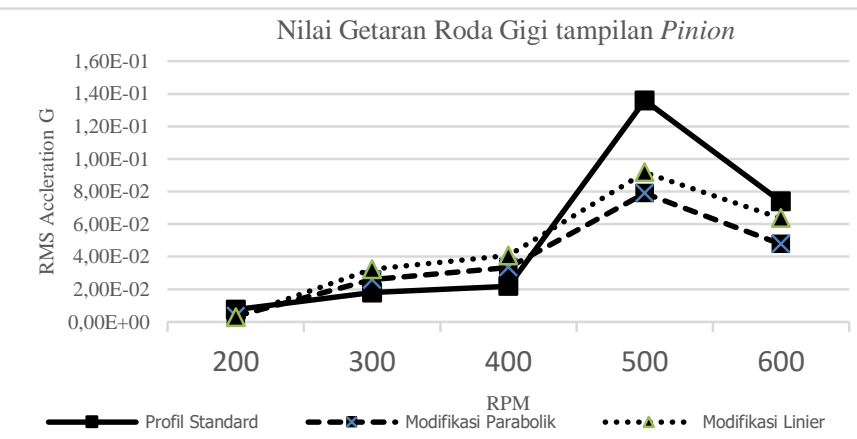

Gambar 14. Contoh Nilai Getaran Profil Standard dan Modifikasi tampilan Pinion

Nilai getaran hasil simulasi selanjutnya diolah dalam bentuk tabel untuk memudahakan komparasi hasil simulasi dan eksperimen. Komparasi ini bertujuan untuk mengetahui perbedaan dan error yang dihasilkan pada hasil simulasi, tabel komparasi tersebut ditunjukkan pada tabel 6.

Tabel 6.

Tabel Getaran dan error Hasil Simulasi dan Eksperimen

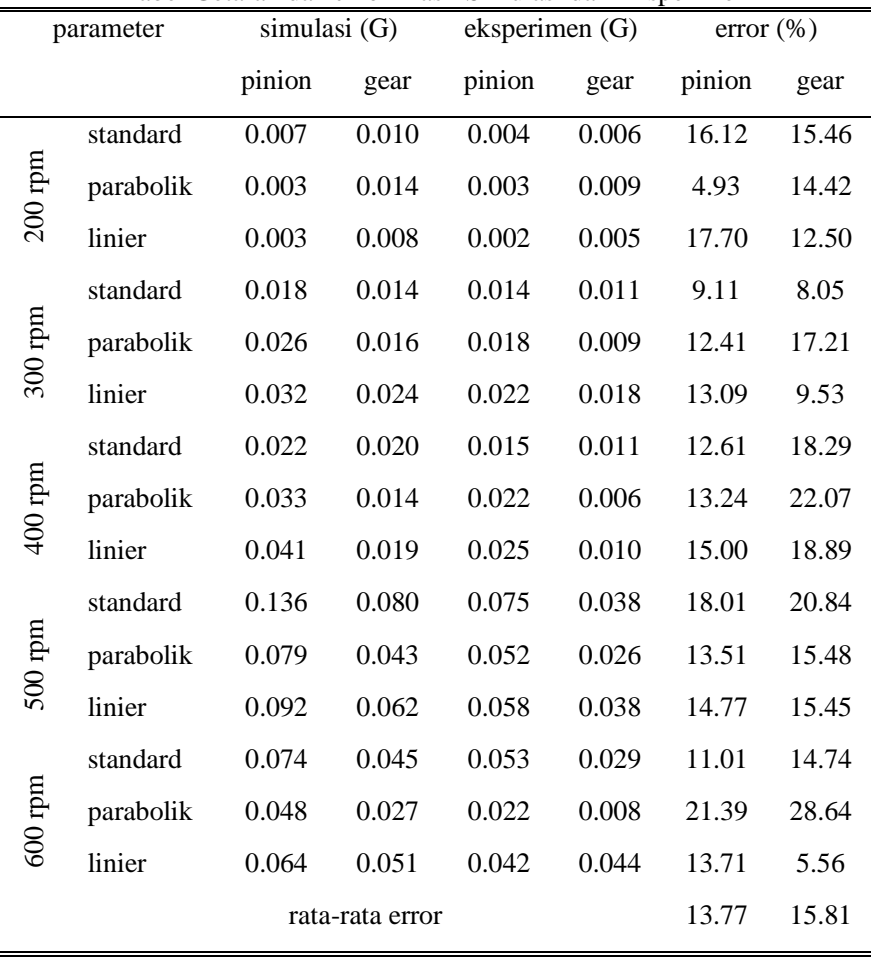

\section{KESIMPULAN}

Kesimpulan dari penelitian tentang komparasi modifikasi profil gigi ini, yaitu:

1. Trendline pada hasil simulasi memiliki bentuk pola kenaikan, penurunan, dan fluktuasi yang cenderung sama pada tiap hasil simulasi jika dibandingkan dengan hasil eksperimen yang diketahui. yang mirip dengan hasil eksperimen, walaupun memiliki nilai yang berbeda
2. Modifikasi profil gigi mengurangi regangan dinamis yang terjadi dengan rincian sebagai berikut :

a) Modifikasi Parabolik mengurangi regangan yang terjadi sebesar $13,42 \%$ pada pinion, dan sebesar $38,726 \%$ pada gear untuk variasi $100 \mathrm{rpm}$. Pada variasi $200 \mathrm{rpm}$ reduksi regangan terjadi sebesar $12,006 \%$ pada pinion dan 7,682 \% pada gear. Selanjutnya, pada variasi $300 \mathrm{rpm}$ reduksi regangan juga terjadi sebesar 13,108 \% pada pinion, namun mengalami kenaikan regangan sebesar 108,586 \% pada gear,

b) Modifikasi Parabolik mengurangi regangan yang terjadi dengan rata-rata sebesar $12,95 \%$ pada pinion dan $9,16 \%$ pada gear,

c) Modifikasi Linier mengurangi regangan yang terjadi sebesar $4,451 \% \%$ pada pinion, dan sebesar $51,818 \%$ pada gear untuk variasi $100 \mathrm{rpm}$. Pada variasi $200 \mathrm{rpm}$ reduksi regangan terjadi sebesar $2,126 \%$ pada pinion dan $15,879 \%$ pada gear. Selanjutnya, pada variasi 300 rpm reduksi regangan juga terjadi sebesar 2,8\% pada pinion, dan sebesar $12,072 \%$ pada gear,

d) Rata-rata reduksi nilai regangan yang terjadi pada modifikasi linier adalah sebesar $3,41 \%$ pada pinion dan $36,44 \%$ pada gear

e) Modifikasi Parabolik mengurangi getaran yang terjadi dengan rata-rata reduksi sebesar $26,34 \%$ pada pinion dan $32,78 \%$ pada gear

f) Modifikasi Linier mengurangi getaran yang terjadi dengan rata-rata reduksi sebesar $10,09 \%$ pada pinion dan $2,63 \%$ pada gear

3. Perbedaan antara hasil simulasi dan eksperimen pada tiap variasi dinyatakan dalam bentuk error. Total error yang terjadi pada keseluruhan simulasi adalah :

a) Hasil simulasi regangan dinamis memiliki rata-rata error sebesar $15,884 \%$ pada pinion, dan sebesar $17,722 \%$ pada gear

b) Perbandingan hasil yang diperoleh pada hasil simulasi getaran memiliki rata-rata error sebesar $13,773 \%$ pada pinion, dan sebesar 15,807\% pada gear

\section{DAFTAR PUSTAKA}

[1] D. W. Dudley, Gear Tooth Design. United State of America: McGraw-Hill Inc, 1992.

[2] A. N. Taufan, "Studi Kekuatan Spur Gear Dengan Profil Gigi Cycloid dan Involut," J. Tek. POMITS, vol. 1, no. 1, 2012.

[3] A. S. Pramono, Experimental Study of The Influence of Tooth Vibration. Swiszerland: Trans Tech Publication Inc, 2006.

[4] S. . Al, Hamrock B.J. et, Jacobson, B., Schmid, Fundamentals of Machine Elements. United State of America: McGraw-Hill, 1999. 